\title{
RESEARCH ON PLASTIC FOOD CONTAINER SAFETY
}

\author{
Ganchimeg L. ${ }^{1}$, Unursaikhan $S .{ }^{2 *}$, Uyanga $G_{.}{ }^{2}$ and Delgermaa $V^{3}$ \\ ${ }^{1}$ Mongolian National Defence University, Mongolia \\ ${ }^{2}$ National Center of Public Health, Mongolia \\ ${ }^{3}$ World Health Organization \\ *corresponding author: e-mail: unursaikhan_surenjav@yahoo.com
}

\section{INTRODUCTION}

Safety of plastic food container is an issue lies within the understanding of "Individual Safety" or "Community Safety", which means that liberty and health of the population for a country should be protected from possible attacks, natural or technical threads. Recently, enormous attention goes to "blue" and "yellow" colored plastic food containers that are used in daily activities of Mongolians, which are actually designated to store and transport chemicals, due to their toxicity and harm caused to human health.

According to American scientist's findings Biphenyl A, component of plastic container, reduces male sex hormones activity, induces breast cancer and reduces spem count. Although plastic containers look clean and tidy, chemicals from the containers lowly transfer to the stored food and cause health risk and accumulating in the body $[1,2]$.

The most dangerous thing about the plastic container is that any symptoms do not occur immediately. But the long-term usage of plastic containers can affect human health by supporting diseases and causing impact on normal function of immune system. Scientists advised that lead and other chemicals released from plastic container can be the cause of many diseases such as diabetes, infertility, dermal diseases and neurological defects $[3,4]$.

In 2008, Public Health Institute ran a research covering 800 households and found that $63 \%$ or majority of the participants answered that they use plastic containers to store and transport their drinking water. Heavy metal contents in the plastic containers used for water storage was 1800-6900 times higher in lead content compare to WHO and Mongolian standards $(0.01 \mathrm{mg} / \mathrm{l})$, and average formalin content was $37.67-53.43 \mathrm{mg} / \mathrm{l}$. Additionally, it was determined that chemical content, transferred from the plastic container to the water, was increasing depending on length of storage [5].

According to chemical census conducted in 2002 throughout Mongolia, 563 types of chemicals were registered and the data showed that 94.5 million plastic bags and 2.7 thousand tons of lubricating materials were imported in 2003. Population widely uses these plastic containers, designated for chemical transportation, for their needs to store and transport yoghurt, milk and dirking water. Therefore, this research was aimed to study plastic containers such as "Big blue colored container" for water, "Yellow colored 
container" for oil and "White colored container" which has no mark and the designation stills remains unclear and other containers most commonly used among Mongolians. The survey was conducted to determine the safety level of plastic food container use and it had following objectives:

To study legislation and regulation on plastic container in Mongolia and determine challenges;

\section{METHODOLOGY}

In total of 320 households including 210 households residing in the territory of Bayangol, Bayanzurkh, Nalaikh, Chingeltei, Songino Khairkhan, Sukhbaatar and KhanUul districts of Ulaanbaatar city and 110 households from Orkhon, Darkhan-Uul and Uvurkhangai province were included in the survey. Statistical data processing was performed by SPSS-21 software. In addition, we have collected a questionnaire from the people who run their small-businesses in the local markets such as "Narantuul" International market, "Kharkhorin" market, "Bumbugur" Trade center in Ulaanbaatar city and largest

\section{RESULTS}

There are laws on food, on maintaining safety of food products, on waste, on hazardous and toxic chemicals and over 30 rules, regulations and over 50 national standards that are implemented in order to regulate packaging in Mongolia.

According to the report of Ministry of Food and Agriculture, Mongolia now produces about $30 \%$ of used packaging and remaining $70 \%$ are supplied from other countries. It means that we spent over 80 million US dollars in average for various types of packaging annually. From 2010 to 2014 and first half of 2015, Mongolia imported plastic and plastic based containers from People's Republic of China, Republic of Korea, United States of America, Poland, Russian Federation, Federal Republic of
To conduct survey on imported plastic containers in Mongolia;

To conduct survey on private companies that produce plastic containers in the territory of Mongolia;

To conduct survey on plastic containers, which are used as household food container;

To conduct survey on plastic containers available in the market and to determine the origin of it.

local markets in Orkhon, Darkhan-Uul and Uvurkhangai provinces. We also analyzed the laws, government decision, order of the minister, regulation and standards followed nationwide in order to study the legislation for plastic container effective within the territory of Mongolia and identify the vital issues faced in the field.

Data on plastic containers imported in Mongolia during 5 years from 2010 to 2015 was analyzed by SPSS-21 software. On top of that, survey and assessment was conducted among private companies that do activities in the production of plastic containers.

Germany, Vietnam, Japan, Australia, Italy and Great Britain and the $97.1 \%$ of this products imported from People's Republic China.

In terms of types of plastic container and products, $60 \%$ of them were imported for containing food, $34 \%$ for laboratory needs, $2.5 \%$ for household needs, $2 \%$ for medical devices and remaining $4 \%$ is for cosmetics, children products, and chemicals and for technical purposes (Figure 1).

Plastic food container accounts for $60 \%$ of the imported products and household plastic container accounts for $1.9 \%$. 


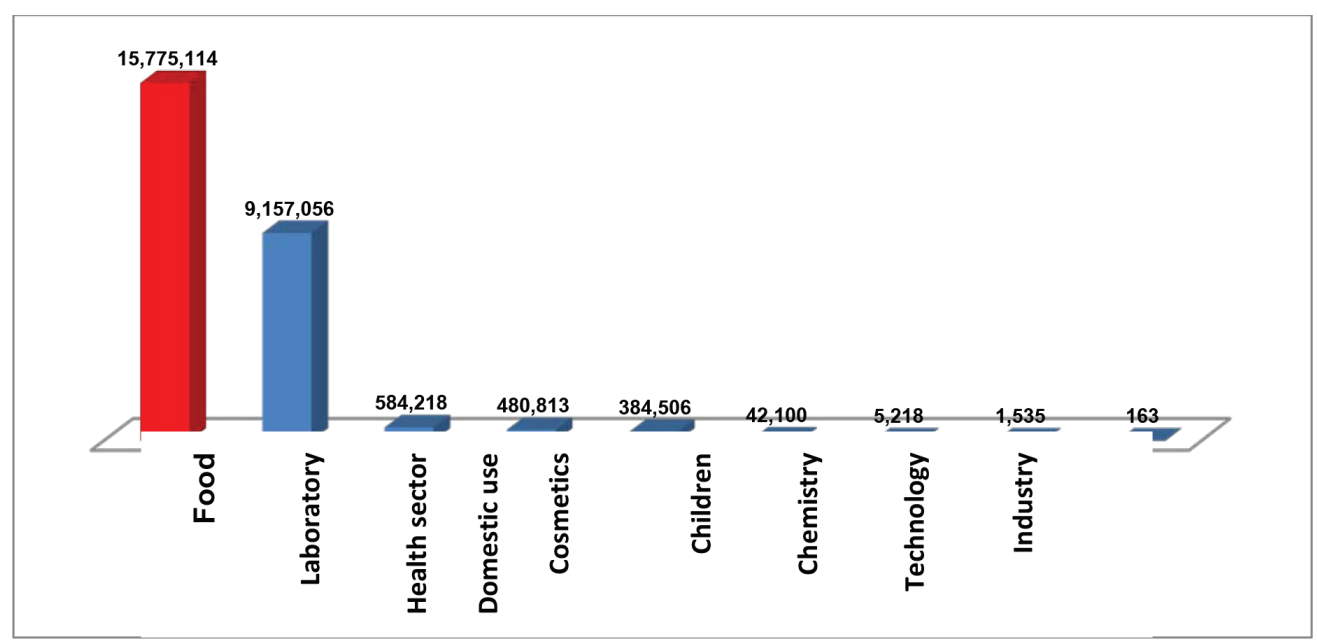

Figure1. Specification and type of plastic products, by peace's

According to the information from Ministry of Food and Agriculture, there are over 30 entities with about 700 employees run their activities to supply $30 \%$ of the packaging consumption in Mongolia. For example, the products worth 50-60 billion tugrik were produced and sold at the market as cardboard box, fabric and paper bags, gift bag, cloth bag, all types of labels, water and drink bottle, packaging, packaging films, packing wrap, caps, plastic container fabrication, plastic bag for food products, book, newspaper, magazine, fiber sacks, polypropylene bags, labels, tissue, notebook, disposable plastic cups, plate and envelope. Polyethylene terephthalate and polypropylene plastic are used for the production of plastic containers as stated in international standards and there is still no specific laboratory to test the raw materials used in the production of plastic containers in Mongolia.

Research was conducted with total 297 participants from city and rural areas and it was found that there were in total 385 plastic containers used for transporting water, mare milk's drink, milk and yoghurt for the food consumption. In terms of the geographical location, 83 or $21.5 \%$ of them were in the city and 302 or $78.4 \%$ were in the rural areas indicating that households in the rural area use 3.6 times higher plastic container than households in the city. But for the plastic containers that are used for food product storage, the results showed that 83 or $21.5 \%$ were in the city and 302 or $78.4 \%$ were in the rural areas, in total 385 plastic containers. Thus, households in city use 5.3 times higher plastic products for food storage than households in rural area.

Totally 227 or $84 \%$ of plastic containers used by the households in the city area(total $=324$ ) were bought from the market, 97 or $16 \%$ were from other sources whereas for rural area, it was 284 or $82 \%$ from market and 61 or $18 \%$ from other sources. By simple eye observation of plastic container conditions used for water storage and transportation we have found that $13.2 \%$ of those in the rural area and $1.8 \%$ for those in the city area had poor rating. $12.5 \%$ of plastic water containers in the rural area and $2.6 \%$ in the city area were rated poor and it clearly illustrates need for developing habit to maintain hygiene and sanitation plastic containers for rural citizens. When there is small amount of water remains in the dirty container, it can be a favorable condition for bacteria to grow causing further contamination on water. 


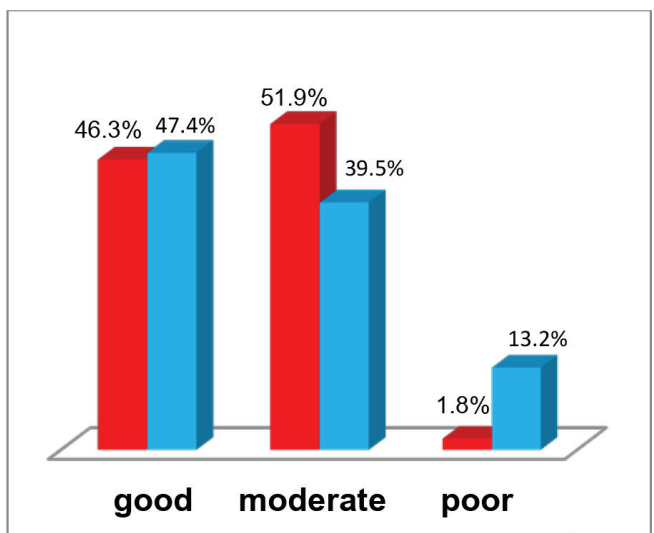

Figure2. Water transporting container hygiene, by location

We surveyed 7 vendors in the market in order to test their knowledge on whether plastic container affects human health, whether they give attention to the labeling and signs on the plastic containers when they sell it the answer was no for all participants. It shows that their knowledge on these issues is not enough. Additionally, survey was conducted on plastic containers sold in the market. We found that there are 38 types of containers in total sold in 2 markets and their average volume was 60 liters. And 17 types or $55.3 \%$ of them were new and 16 or $44.7 \%$ were old, used containers.

In terms of sources of containers, $47.1 \%$

\section{CONCLUSIONS}

Although there are laws, regulations and standards to regulate packaging in Mongolia, there are no connections in between and implementation of them seems insufficient. Therefore, it is required to develop general policy about the disposal of plastic chemical container and monitor the implementation.

The documents such as "Regulation on Importing and exporting, cross-border transportation, production and trade of Hazardous and Toxic chemicals" and "Storage, transportation, utilization and disposal of Hazardous and Toxic chemicals" do not fully regulate the detailed concerns about importing, disposal and trade of empty containers for

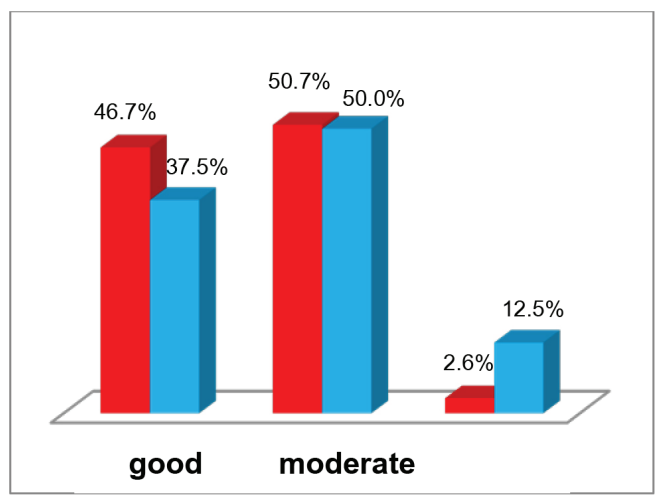

Figure3. Water storage container hygiene, by location

were imported from foreign countries (People's Republic of China, Germany, Malaysia, Russian Federation, Republic of Korea) with volume of 20, 50, 120, 160, 220 and 300 liters; and $52.9 \%$ were supplied from domestic sources (MCS, Uguuj, pastry factory, restaurant, individual, emulsion container) via certain people from food and leather factories and mining companies. Average volume for the plastic containers imported from foreign countries was 100 liters and average volume of plastic containers from domestic sources was 20 liters.

chemicals. The related authorities should check whether entities and organizations dispose them as stipulated in the law.

It is required to establish a system to issue permission for private sector entities to operate a production of plastic containers after determining whether raw materials used in the production are polyethylene terephthalate and polypropylene plastic or not.

The policy and the government support are needed for food specified plastic container producers.

Use of plastic containers among Mongolians is very broad because it is light and comfortable to use, indicating that 
people's choice does not depend on price of the product. There is lack of knowledge about labeling of plastic container, its health impact and adequate use in both urban and rural areas.

$44.9 \%$ of the plastic containers sold in the trade markets are old (used) and it allows an opportunity for the citizens to buy the containers that are not specified for food storage.

Narantuul International Trade Center in Ulaanbaatar city is the first point of selling of
$55 \%$ of plastic containers sold in the rural area markets.

It is must to organize a training and other advertising activates to improve knowledge about harmful effects from plastic containers, own health protection for vendors and for people who buy it.

Safety of food packaging in Mongolia is lost and it is at the level of health risk to citizens.

\section{REFERENCES}

1 Food safety and contaminants and toxins ed. by J.P.F. Mello, CABI Publishing Cambridge, 2003

2 International food safety Handbook, Van Der Hegiden, K.M.Fishbein, Marcel Dekker, Inc. New York, Basel 1999

3 Nutritional and Toxicological Aspects of Food Safety, Freidman, M.Plenum, press. New York 1985

4 "Toxicology of foods and Health" Tsevegsuren.N., Saruul.I., Ulaanbaatar, 2004

5 "Water quality and hygiene" Report of study, Public Health Institute, 2008 